\title{
Compression-Coated Tablet for Colon Targeting: Impact of Coating and Core Materials on Drug Release
}

\author{
Siddhartha Maity ${ }^{1}$ and Biswanath $\mathrm{Sa}^{1,2}$
}

\begin{abstract}
Received 31 March 2015; accepted 19 June 2015; published online 14 August 2015
Abstract. This work was envisaged to develop compression-coated tablets using a blend of $\mathrm{Ca}^{+2}$ ion crosslinked carboxymethyl xanthan gum (CMXG) and sodium alginate (SAL) for delayed release of immediate pulse release tablets of prednisolone (PDL) in the colon without the need of colonic bacterial intervention for degradation of the polysaccharide coat. The core tablets containing PDL and other compatible excipients were prepared by direct compression method and subsequently compression coated with different ratios of CMXG and SAL. Long $T_{\text {lag }}$, the time required to restrict the drug release below $10 \%$, and short $T_{\text {rap }}$, the time required for immediate release following the $T_{\text {lag, }}$, were considered as suitable release parameters for evaluation of colon targeting of PDL tablets. Among the various compression coats, a blend of CMXG and SAL in a ratio of 1.5:3.5 provided $T_{\text {lag }}$ of $5.12 \pm 0.09 \mathrm{~h}$ and $T_{\text {rap }}$ of $6.50 \pm 0.05 \mathrm{~h}$. The increase in microcrystalline cellulose (MCC) and crospovidone (CP) in the core tablets did not change $T_{\text {lag }}$ significantly although decreased the $T_{\text {rap }}$ marginally. Inclusion of an osmogen in the core tablets decreased the $T_{\text {lag }}$ to $4.05 \pm 0.08 \mathrm{~h}$ and $T_{\text {rap }}$ to $3.56 \pm 0.06 \mathrm{~h}$. The increase in coat weight to $225 \mathrm{mg}$ provided a reasonably long $T_{\text {lag }}(6.06 \pm 0.09 \mathrm{~h})$ and short $T_{\text {rap }}(4.36 \pm 0.20 \mathrm{~h})$. Drug release from most of the formulations followed the Hixson-Crowell equation and sigmoidal pattern as confirmed by the Weibull equation. In conclusion, tablets, compression coated with CMXG and SAL in a ratio of 1.5:3.5 and having 225-mg coat weight, were apparently found suitable for colon targeting.
\end{abstract}

KEY WORDS: colon targeting; compression coating; drug release; prednisolone; release kinetic.

\section{INTRODUCTION}

Colon targeting of drugs for the treatment of colonrelated diseases such as Crohn's disease, ulcerative colitis, inflammatory bowel syndrome, colorectal cancer, amebiasis, etc. has become one of the thrust areas in pharmaceutical research (1). When compared with conventional oral dosage forms, colon-targeted drug delivery systems offer potential advantages like delivery of high local drug concentration at the afflicted site of the colon to produce optimum therapeutic action and reduction in systemic adverse effects associated with premature release and subsequent absorption of drugs from the upper gastrointestinal tract (g.i.t.) (2-4).

Pharmaceutical approaches, which have been adopted for colon targeting of drugs, include $\mathrm{pH}$-sensitive system, timedependent release system, and microbially triggered system which includes prodrug and polysaccharide-based system. $\mathrm{pH}-$ sensitive systems exhibit unpredictable site specificity of drug release because of inter- and intrasubject variation and almost similar $\mathrm{pH}$ values of small intestinal and colonic fluids (5). A time-dependent system seems difficult for accurate prediction of site for drug release because of wide variation in gastric

\footnotetext{
${ }^{1}$ Division of Pharmaceutics, Department of Pharmaceutical Technology, Jadavpur University, Kolkata, 700032, India.

${ }^{2}$ To whom correspondence should be addressed. (e-mail: biswanathsa2003@yahoo.com)
}

retention time (6) though the small intestinal transit time $(3 \pm$ $1 \mathrm{~h}$ ) is relatively constant and less variable (7). Prodrugs based on azo polymers are specifically reduced by azoreductase enzymes. However, they are expensive and their safety is questionable (8). Microbially triggered systems are based on compression coating of immediate release tablets with natural polysaccharides which are degraded by anaerobic microflora of the colon $(5,9)$. However, various factors may quantitatively change the composition of the human gut ecosystem $(10,11)$. Moreover, a larger amount of coat is required to prevent premature drug release due to higher hydrophilicity of the polysaccharides (12). On the other hand, thicker coating, although minimizes precolonic release, induces sustained release following a reasonable lag time instead of burst release of drugs in the absence of specific enzymes or cecal content (13-15). A general and indeed a more rational approach is, therefore, to develop a compression-coated tablet, the coat of which should erode slowly enough to prevent or at least to minimize the precolonic release and then to provide an immediate burst release of drugs in the colon irrespective of enzymatic metabolism of the polysaccharides by colonic microflora. For such a drug delivery system, $T_{\text {lag, }}$, the time required to prevent or at least restrict the drug release to a minimum (say $<10 \%$ ), should be long usually $6 \mathrm{~h}$ (inclusive of $2 \mathrm{~h}$ gastric empting time in an empty stomach and $3 \mathrm{~h}$ small intestinal transit time and $1 \mathrm{~h}$ buffer time for any delay in transit), and $T_{\text {rap }}$, the time required for immediate pulse 
release in the absence of colonic enzyme or cecal content following the $T_{\text {lag }}$, should be short (say 4-6 h), and thus, the release pattern should conform to a sigmoidal curve.

Although several polysaccharides such as guar gum, pectin, sodium alginate, locust bean gum, chitosan, boswellia gum, and xanthan gum have been used as compressioncoating material (16-20), carboxymethyl xanthan gum (CMXG), neither alone nor in combination with other polysaccharides, has been explored to assess its suitability for the development of compression-coated colon-targeted tablets. In a previous study, we evaluated $\mathrm{Ca}^{+2}$ ion cross-linked CMXG (Ca-CMXG) matrix tablets for colon delivery of prednisolone (PDL) (21). That study revealed that although Ca-CMXG matrix tablets released considerably less amount of drug in the initial $5 \mathrm{~h}$, none of the tablets was able to produce rapid and complete release in the following $5 \mathrm{~h}$, and thus, CaCMXG matrix tablets were found unsuitable as colontargeting device. In another study, in which we evaluated the swelling and erosion characteristics of Ca-CMXG matrix tablets, it was observed that the increase in the amount of $\mathrm{Ca}^{+2}$ ion increased the erosion of the matrix (22). Considering the high release retarding ability of $\mathrm{Ca}-\mathrm{CMXG}$ and higher erosional characteristics at higher $\mathrm{Ca}^{+2}$ ion level, it was reasonable to examine whether $\mathrm{Ca}-\mathrm{CMXG}$, either alone or in combination with other polysaccharide, could be used as a compression-coating material in developing colon-targeted tablet.

In this study, core tablets of PDL for immediate pulse release were developed and subsequently compression coated with $\mathrm{Ca}-\mathrm{CMXG}$ with or without sodium alginate. In vitro release of PDL from the resulting compression-coated tablets was evaluated in a dissolution medium devoid of any enzyme or simulated colonic fluid. The intention of this study was to develop a compression-coated tablet that can restrict the premature drug release to or below $10 \%$ for at least $6 \mathrm{~h}$ and thereafter provide almost a complete release within 4-6 h. Prednisolone has been chosen as a model drug because of its local pharmacological effect in colonic diseases (10).

\section{MATERIALS AND METHODS}

\section{Materials}

PDL was obtained from Mepro Pharmaceuticals, Mumbai, India. CMXG, having a degree of substitution of 0.8 , was synthesized in our laboratory. Sodium alginate (SAL), $\mathrm{CaCl}_{2}$, $2 \mathrm{H}_{2} \mathrm{O}\left(\mathrm{CaCl}_{2}\right)$, microcrystalline cellulose (MCC, $\mathrm{PH} 102$ ), polyplasdone $\mathrm{XL}$ (crospovidone, $\mathrm{CP}$ ), trisodium citrate (TSC), magnesium stearate (MS), and trisodium orthophosphate dodecahydrate (TSP) were purchased commercially. All other reagents and solvents of analytical grade were used throughout the study.

\section{Preparation and Characterization of CMXG}

Conversion of XG to CMXG and its characterization have been reported elsewhere (22). In brief, a required amount of XG was sprinkled slowly for $30 \mathrm{~min}$ in alkaline solution at $0-8{ }^{\circ} \mathrm{C}$. After complete hydration, $45 \% w / v$ monochloroacetic acid solution was added slowly at $15-18^{\circ} \mathrm{C}$ and the temperature was increased to $75^{\circ} \mathrm{C}$. After $1 \mathrm{~h}$, the mass was washed repeatedly with $80 \% v / v$ methanol solution, and finally, the $\mathrm{pH}$ of the mixture was made neutral with glacial acetic acid. The resulting CMXG was dried at 45$50^{\circ} \mathrm{C}$ to constant weight. Formation of $\mathrm{CMXG}$ was ascertained by Fourier transform infrared (FTIR), DSC, $\mathrm{XRD},{ }^{1} \mathrm{H}-\mathrm{NMR}$, and elemental analyses.

\section{Preparation of the Core Tablet}

Core tablets having a crushing strength of about $4 \mathrm{~kg}$ were prepared by direct compression method. PDL and various amounts of excipients such as MCC, CP, MS, and TSC were passed through a \#60 BS screen, blended manually, and compressed into tablets using a flat face $5.5-\mathrm{mm}$ punch in a 10 station rotary minipress tablet machine (RIMEK, Karnavati Engineering Ltd., Gujarat, India). The composition of the core tablets is shown in Table I. Fifty tablets of each formulation were prepared in duplicate.

\section{Preparation of the Compression-Coated Tablet}

Granules containing different ratios of CMXG and SAL and having size \#18 to \#22 mesh (BS screen) were prepared by wet granulation method with the aid of a required amount of $\mathrm{CaCl}_{2}$ solution and were used as compression-coating material. To prepare compression-coated tablets of crushing strength of about $6 \mathrm{~kg}, 40 \%$ of the granules were placed in $8-\mathrm{mm}$ die, the core tablet was placed centrally in the die cavity, and the remaining $60 \%$ of granules were poured in the die cavity and finally compressed using 8-mm punch. The composition of the compression-coated tablets is shown in Table II. Fifty tablets of each formulation were prepared in duplicate.

\section{Physical Characteristics of the Tablets}

\section{Weight Variation}

Twenty core tablets and compression-coated tablets were weighed individually in an electronic pan balance (XB 600MC, Precisa, Switzerland). The weight of each tablet was compared with the respective average weight of the tablets.

\section{Crushing Strength}

The crushing strength of the core tablets and compression-coated tablets was determined using a Monsanto type tablet hardness tester (Campbell Electronics, Mumbai, India), and the average value of ten determinations was reported.

\section{Thickness}

The thickness of the core tablet and compression-coated tablet was measured with a Digimatic Caliper (CD-6"CS, Mitutoyo Corporation, Japan), and the average of ten determinations was calculated.

\section{Friability}

Ten core tablets and ten compression-coated tablets were weighed and placed in a plastic drum of a friabilator (EF2, 
Table I. Composition and Physical Properties of the Core Tablets

\begin{tabular}{|c|c|c|c|c|c|c|c|c|}
\hline \multirow[t]{2}{*}{ Code } & \multicolumn{4}{|c|}{$\begin{array}{l}\text { Composition of core } \\
\text { tablets }(\mathrm{mg})\end{array}$} & \multirow[t]{2}{*}{$\begin{array}{l}\text { Weight of core tablets } \\
\quad(\mathrm{mg})(\text { mean } \pm \mathrm{SD}, n=20)\end{array}$} & \multirow[t]{2}{*}{$\begin{array}{l}\text { Drug content }(\mathrm{mg}) \\
\quad(\text { mean } \pm \mathrm{SD}, n=10)\end{array}$} & \multirow[t]{2}{*}{$\begin{array}{l}\text { Tablet thickness }(\mathrm{mm}) \\
\quad(\text { mean } \pm \mathrm{SD}, n=10)\end{array}$} & \multirow[t]{2}{*}{ Tablet friability (\%) } \\
\hline & MCC & $\mathrm{CP}$ & TSC & PDL & & & & \\
\hline $\mathrm{C} 1$ & 55 & 4 & 0 & 5 & $64.47 \pm 2.14$ & $5.03 \pm 0.25$ & $2.82 \pm 0.025$ & 0.72 \\
\hline $\mathrm{C} 2$ & 75 & 4 & 0 & 5 & $84.65 \pm 1.44$ & $4.79 \pm 0.17$ & $3.04 \pm 0.024$ & 0.71 \\
\hline $\mathrm{C} 3$ & 90 & 4 & 0 & 5 & $99.29 \pm 2.03$ & $5.06 \pm 0.15$ & $3.97 \pm 0.043$ & 0.89 \\
\hline $\mathrm{C} 4$ & 55 & 9 & 0 & 5 & $70.16 \pm 2.35$ & $4.77 \pm 0.15$ & $2.95 \pm 0.033$ & 0.64 \\
\hline $\mathrm{C} 5$ & 55 & 14 & 0 & 5 & $75.82 \pm 1.61$ & $4.79 \pm 0.18$ & $3.03 \pm 0.034$ & 0.96 \\
\hline C6 & 55 & 9 & 5 & 5 & $75.93 \pm 1.64$ & $4.81 \pm 0.11$ & $2.84 \pm 0.047$ & 0.90 \\
\hline $\mathrm{C} 7$ & 55 & 9 & 10 & 5 & $80.51 \pm 1.74$ & $5.11 \pm 0.10$ & $2.95 \pm 0.033$ & 0.79 \\
\hline $\mathrm{C} 8$ & 55 & 9 & 20 & 5 & $90.54 \pm 1.84$ & $4.86 \pm 0.20$ & $3.29 \pm 0.036$ & 0.93 \\
\hline C9 & 55 & 9 & 10 & 10 & $86.01 \pm 1.30$ & $9.67 \pm 0.17$ & $3.03 \pm 0.055$ & 0.75 \\
\hline $\mathrm{C} 10$ & 55 & 9 & 10 & 15 & $90.77 \pm 2.16$ & $14.95 \pm 0.12$ & $3.22 \pm 0.039$ & 0.77 \\
\hline
\end{tabular}

$M C C$ microcrystalline cellulose, $C P$ crospovidone, $T S C$ trisodium citrate, $P D L$ prednisolone

Electro Lab, Mumbai, India). After 100 revolutions, the tablets were dedusted with a soft brass and reweighed. The percentage of weight loss was calculated.

\section{Drug Content}

A core tablet was crushed in a glass mortar and transferred quantitatively with methanol in a stoppered conical flask. The flask was shaken in a mechanical shaker for $4 \mathrm{~h}$. The mixture was filtered and an aliquot, following suitable dilution, was analyzed at $243 \mathrm{~nm}$ using a microplate spectrophotometer (Multiskan Go, Thermo Scientific, USA). The drug content was determined using a calibration curve constructed in methanol. The drug content of each of the ten core tablets was compared with the average drug content of the tablets.

\section{Fourier Transform Infrared Analysis}

The FTIR spectra of PDL and PDL-loaded core tablet containing all the excipients (MCC, CP, TSC, and MS) were recorded in a FTIR spectrophotometer (Perkin Elmer, RX-1, UK). The samples were mixed with $\mathrm{KBr}$ and converted into pellets using a hydraulic press. The spectra were taken in the wave number region of 4000$400 \mathrm{~cm}^{-1}$.

\section{In Vitro Drug Release Study}

In vitro drug release study was carried out in USP-II tablet dissolution rate test apparatus (TDP-06P, Electro Lab, Mumbai, India) at $37 \pm 0.5^{\circ} \mathrm{C}$ with $100 \mathrm{rpm}$ speed under sink condition following the method described in Indian Pharmacopoeia 2010 (23) for modified release tablet with slight modification. The compression-coated tablets of each formulation were immersed in $700 \mathrm{ml} \mathrm{HCl}$ solution of $\mathrm{pH} 1.2$ (gastric $\mathrm{pH}$ ), and the study was carried out for $2 \mathrm{~h}$. Thereafter, $200 \mathrm{ml}$ of 0.2 (M) trisodium orthophosphate dodecahydrate solution was added quickly and $\mathrm{pH}$ was adjusted using a $\mathrm{pH}$ meter (Orion 2 Star, Thermo Scientific, Singapore) to 7.4 (small intestinal $\mathrm{pH}$ ), and the study was carried out for $3 \mathrm{~h}$ in $900 \mathrm{ml}$ solution of $\mathrm{pH}$ 7.4. After $5 \mathrm{~h}$, the $\mathrm{pH}$ of the dissolution medium was adjusted to $\mathrm{pH} 6.8$ (colonic $\mathrm{pH}$ ) by adding 5-ml 2 (M) $\mathrm{HCl}$, and the study was continued up to $14 \mathrm{~h}$ in $905 \mathrm{ml}$ of dissolution medium. During the release study, 5-ml aliquot was withdrawn from the dissolution medium at a predetermined time and replaced with $5 \mathrm{ml}$ of the fresh respective fluid warmed at $37^{\circ} \mathrm{C}$. The aliquots were filtered through Whatman (no. 1) filter paper. The absorbance was measured spectrophotometrically at $248 \mathrm{~nm}$ for both acid solution of $\mathrm{pH} 1.2$ and buffer solutions of $\mathrm{pH}$ 7.4 and 6.8. The amount of drug released from the tablet was determined using calibration curves drawn in the respective medium.

\section{Viscosity Measurement}

Two percent $(w / v)$ dispersions of $\mathrm{CMXG} / \mathrm{SAL} / \mathrm{CaCl}_{2}$ in different ratios, simulating the compression-coating material, were prepared in acid solution of $\mathrm{pH} 1.2$ and kept for $48 \mathrm{~h}$. The viscosities of the solutions were measured in a rheometer (Anton Parr MCR102, Austria, Europe) using a cone and plate apparatus (D-CP/3, diameter $40 \mathrm{~mm}$, gap between the cone and plate $0.08 \mathrm{~mm}$ ).

\section{Scanning Electron Microscopic Study}

Compression-coated tablets before and at different periods of the dissolution study were collected, dried, and mounted onto stubs using double-sided adhesive tape and sputter coated with gold using a sputter coater (S150, Edward, UK). The coated tablets were observed under a scanning electron microscope (JSM-5200, Jeol, Japan) at $\times 30$ magnification. The acceleration voltage used was $10 \mathrm{kV}$.

\section{Data Treatment}

To understand the mechanism of the drug dissolution from the various compression-coated tablets, the dissolution/ release data after the lag period $\left(T_{\text {lag }}\right)$ were fitted in various 


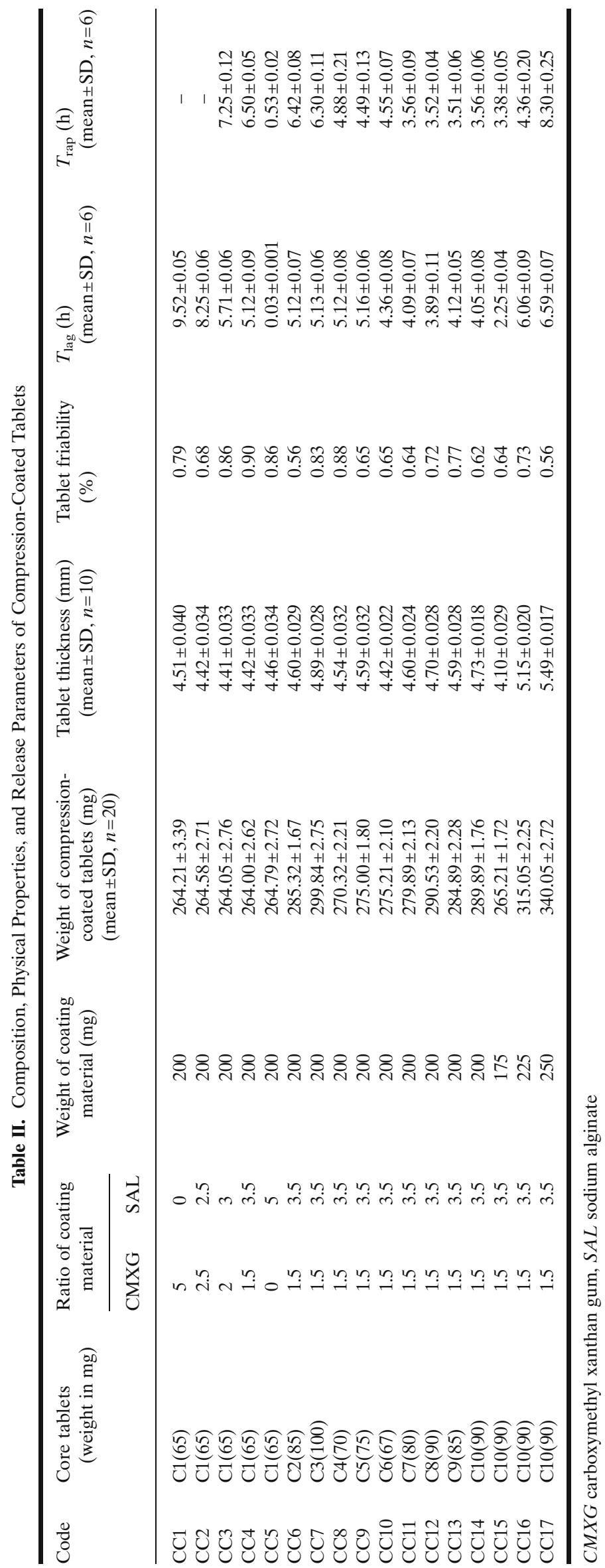


equations, such as zero order Eq. (1), 1st order Eq. (2), and Hixson-Crowell Eq. (3) (24).

$Q_{t}=K_{0} t$

where $Q_{t}$ is the amount of drug released in time $t$, and $K_{0}$ is the zero order release rate constant.

$Q_{t}=Q_{0} \cdot \mathrm{e}^{-K_{1} t}$

where $Q_{t}$ is the amount of drug released in time $t, Q_{0}$ is the initial amount of the drug in the tablet, and $K_{1}$ is the first order release rate constant.

$W_{0}^{1 / 3}-W_{t}^{1 / 3}=K_{\mathrm{s}} t$

where $W_{0}$ is the initial amount of the drug in the formulation, $W_{t}$ is the remaining amount of the drug in the formulation at time $t$, and $K_{\mathrm{s}}$ is the constant incorporating surface to volume ratio.

In addition, to examine which dissolution curves were sigmoidal in shape, the release data were fitted in Weibull Eq. (4) (24) which is as follows:

$m=1-\exp \left[-\left(t-T_{\mathrm{lag}}\right)^{\beta} / \alpha\right]$

where $m$ is the accumulated fraction of the drug in dissolution medium at time $t, \alpha$ is the time scale of the process, $T_{\text {lag }}$ is the lag period before the onset of dissolution or release process, and $\beta$ is the shape parameter which characterizes the curve as either exponential $(\beta=1)$ (case 1$)$; sigmoid, S-shaped with upward curvature followed by a turning point $(\beta>1)$ (case 2$)$; or parabolic, with a higher initial slope and after that consistent with the exponential $(\beta<1)$ (case 3$)$.

\section{Statistical Analysis}

The effect of various formulation parameters on drug release characteristics such as time required for $10 \%$ release ( $\left.T_{\text {lag }}\right)$ and rapid release $\left(T_{\text {rap }}\right)$ following the $T_{\text {lag }}$ was statistically compared by analysis of variance (one-way ANOVA) with the aid of GraphPad Prism (Version 3.0). Difference was considered significant when $p<0.05$.

\section{RESULTS}

The composition and physical properties of the core tablets of PDL prepared with various amounts of MCC and CP with or without TSC are shown in Table I. The weight of the tablets (C1, C4-C6) weighing less than $80 \mathrm{mg}$ did not vary by more than $10 \%$ of the average weight. The weights of the other tablets weighing between 80 and $250 \mathrm{mg}$ were found confined within $\pm 7.5 \%$ of the average weight. The amount of PDL in each of the tablets was within $\pm 15 \%$ of the labeled potency. Friability of the tablets was less than $1 \%$. Thus, the physical properties of the core tablets complied with the limits of variation prescribed in Indian Pharmacopoeia. Moreover, the thickness of the tablets varied within $\pm 5 \%$ of the average thickness. All the core tablets having a crushing strength of $4 \mathrm{~kg}$ disintegrated within $30 \mathrm{~s}$.

The composition and physical properties of the compression-coated tablets having a crushing strength of $6 \mathrm{~kg}$ are shown in Table II. The weight and friability of the tablets were, respectively, within $\pm 5 \%$ and less than $1 \%$ and complied with the requirement of Indian Pharmacopoeia. In addition, the thickness of the tablets did not vary by more than $\pm 5 \%$ of the average thickness.

The FTIR spectra of PDL and core tablets containing maximum amounts of all the excipients are shown in Fig. 1. The spectrum of PDL exhibited peaks at 3496, 3455, and $3356 \mathrm{~cm}^{-1}$ for three $-\mathrm{OH}$ groups, $1609 \mathrm{~cm}^{-1}$ for diene, and 1654 and $1710 \mathrm{~cm}^{-1}$ for 3,20-dione, which were considered for the identification of PDL. The spectrum of the core tablets containing PDL demonstrated the above peaks on the same wave numbers.

The release of PDL from the core tablet in dissolution medium of $\mathrm{pH} 6.8$ was rapid and $95-99 \%$ of the loaded drug was released within $15 \mathrm{~min}$ (data not shown). The release profiles of the drug from various compression-coated tablets are shown in Fig. 2. Tablet CC1 which was coated with $\mathrm{Ca}^{+2}$ ion cross-linked CMXG released only $5.19 \pm 0.11 \%$ and $21.04 \pm$ $1.37 \%$ drug, respectively, in 7 and $14 \mathrm{~h}$.

Substitution of CMXG with an increasing amount of SAL in the coat, as in tablets $\mathrm{CC} 2$ to $\mathrm{CC} 4$, increased the release of the drug. Tablet CC5, which was compression coated with $\mathrm{Ca}^{+2}$ ion cross-linked SAL, released the drug rapidly within $45 \mathrm{~min}$. Table II compares the values of $T_{\text {lag }}$, the time required to release $<10 \%$ of the loaded drug, and $T_{\text {rap }}\left(T_{90-10 \%}\right)$, the time required for rapid pulse release after the $T_{\text {lag }}$, of the tablets coated with cross-linked CMXG and SAL in different ratios. The $T_{\text {lag }}$ value for tablet $\mathrm{CC} 1$ which was coated with only cross-linked CMXG was $9.52 \pm 0.05 \mathrm{~h}$. Substitution of CMXG with an increasing amount of SAL decreased the values of both $T_{\text {lag }}$ and $T_{\text {rap. }}$ Tablet CC5 which was coated

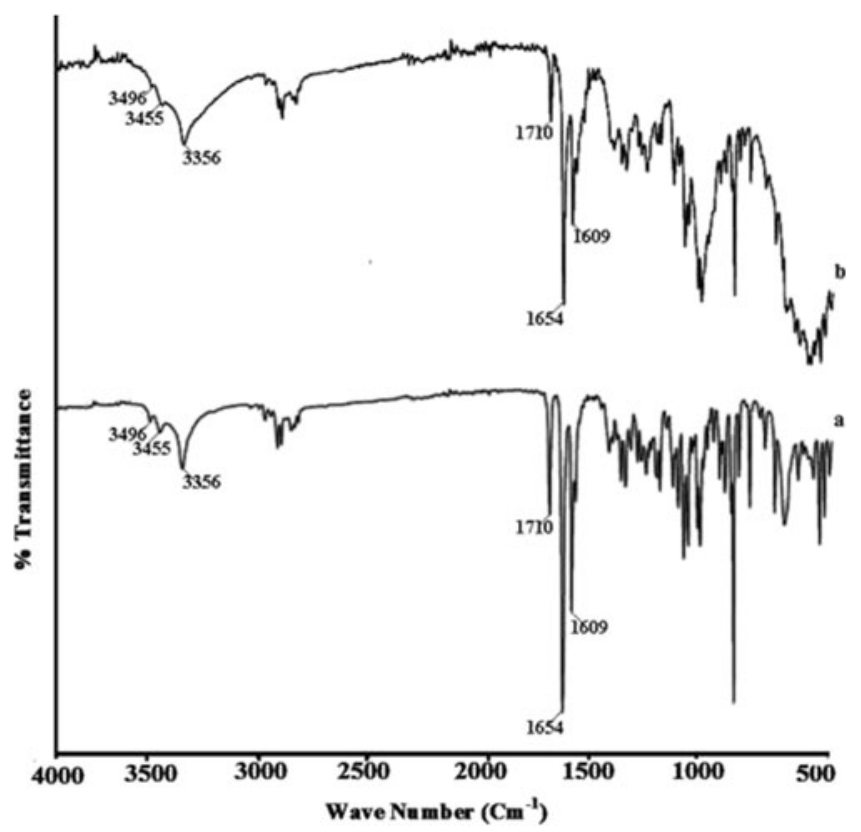

Fig. 1. FTIR spectra of $a$ PDL and $b$ PDL-loaded core tablet 


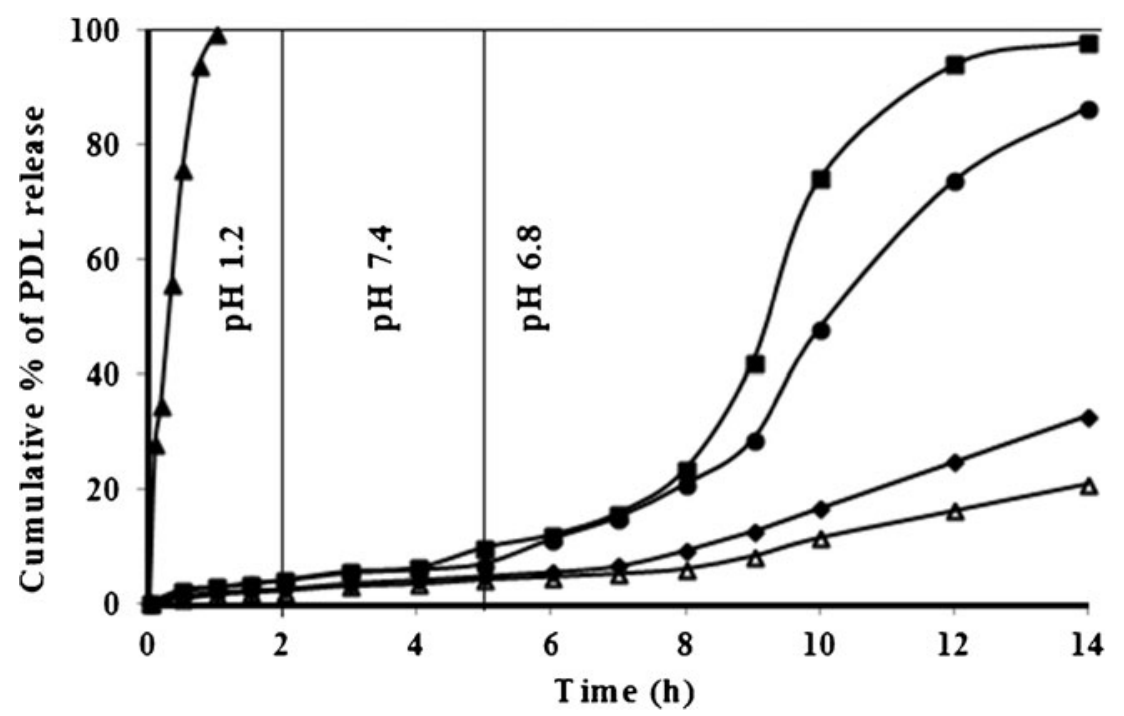

Fig. 2. Effect of coating material on cumulative \% of PDL release from compressioncoated tablet. Key: $\mathrm{CC} 1$, empty triangle; $\mathrm{CC} 2$, filled diamond; $\mathrm{CC} 3$, filled circle; $\mathrm{CC} 4$, filled square; CC5, filled triangle. Maximum SD $( \pm 2.56, n=6)$

with cross-linked SAL alone exhibited very short $T_{\text {lag }}(0.03 \pm$ $0.001 \mathrm{~h})$ and $T_{\text {rap }}(0.53 \pm 0.02 \mathrm{~h})$.

The viscosity of various polymeric solutions containing $\mathrm{CaCl}_{2}$ in acid solution of $\mathrm{pH} 1.2$ is shown in Fig. 3. The viscosity of CMXG solution was very high. Substitution of CMXG with an increasing amount of SAL decreased the viscosity of the bipolymeric gel layer, and the viscosity of the SAL solution was the lowest.

Keeping the composition of the compression-coated material $(\mathrm{CMXG} / \mathrm{SAL}=1.5: 3.5)$ fixed, the effect of variation in the core composition on drug release profiles was studied. The effect of the increase in the amount of MCC in the core tablets (CC4, CC6, and CC7) is shown in Fig. 4. The increase in the amount of MCC from 55 to $75 \mathrm{mg}$ in the core tablet made the drug release faster, although further increase in MCC to $90 \mathrm{mg}$

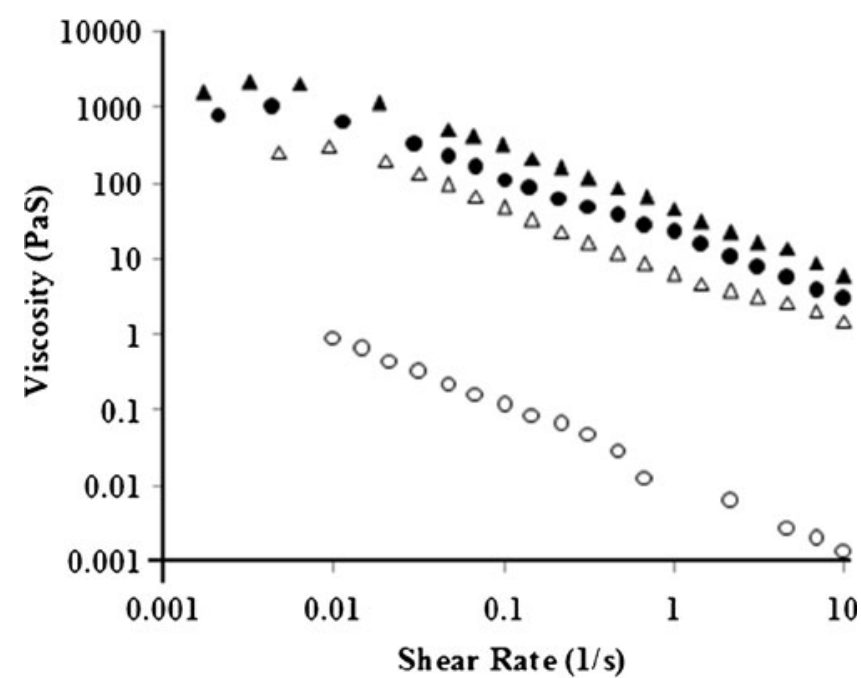

Fig. 3. Viscosity profiles of various blends of coating polymers in acid solution of $\mathrm{pH}$ 1.2. Key: $\mathrm{CC} 1$, filled triangle; $\mathrm{CC} 3$, filled circle; $\mathrm{CC} 4$, empty triangle; $\mathrm{CC} 5$, empty circle did not increase the drug release. Comparison of area under the curves (AUCs) of \% drug release versus time profiles of tablets CC6 and CC7 by $t$ test did not reveal any significant difference $(p>0.05)$. When $T_{\text {lag }}$ of tablets CC4, CC6, and CC7 were compared with analysis of variance (one-way ANOVA) test, no significant change $(p>0.05)$ was observed, although $T_{\text {rap }}$ of the tablets tended to decrease marginally but significantly $(p<0.05)$ with the increase in the amount of MCC.

The effect of $\mathrm{CP}$ in the core tablets on drug release profiles (Fig. 5) and $T_{\text {lag }}$ and $T_{\text {rap }}$ was investigated with tablets $\mathrm{CC} 4, \mathrm{CC} 8$, and CC9. The increase in the amount of $\mathrm{CP}$ in the core tablets increased the release of the drug after the $T_{\text {lag }}$ period. Moreover, the value of $T_{\text {rap }}$ decreased significantly $(p<0.05)$, although no significant change $(p>0.05)$ in $T_{\text {lag }}$ was evident (Table II).

The effect of the inclusion of TSC as an osmogen in the core tablets on drug release profiles (Fig. 6) and $T_{\text {lag }}$ and $T_{\text {rap }}$ was studied with tablets CC10, CC11, and CC12. The drug release from the tablets containing TSC was much faster than

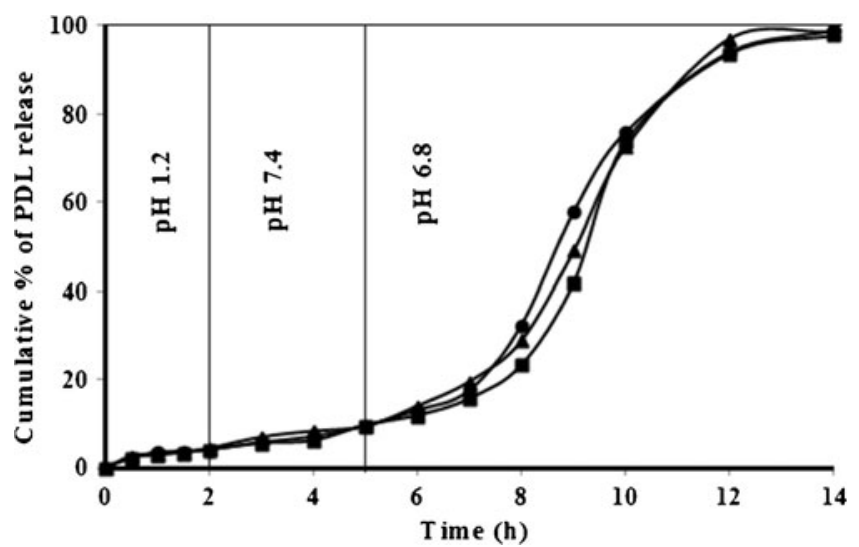

Fig. 4. Effect of MCC in core on cumulative \% of PDL release from compression-coated tablet. Key: CC4, filled square; CC6, filled circle; $\mathrm{CC} 7$, filled triangle. Maximum SD $( \pm 2.46, n=6)$ 


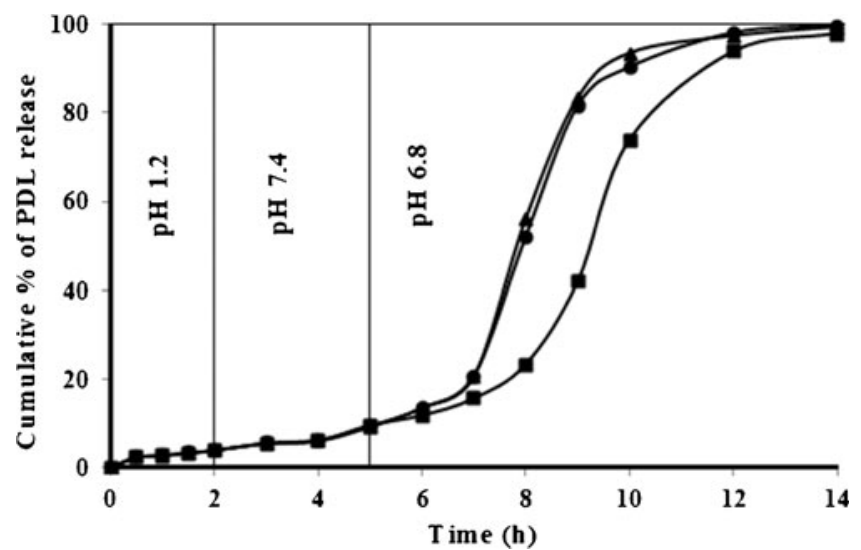

Fig. 5. Effect of $\mathrm{CP}$ in core on cumulative \% of PDL release from compression-coated tablet. Key: CC4, filled square; CC8, filled circle; $\mathrm{CC} 9$, filled triangle. Maximum SD $( \pm 3.28, n=6)$

that from a similar tablet (CC8) without containing TSC (Fig. 5). Further, the inclusion of the osmogen not only reduced $T_{\text {rap }}$ but also decreased $T_{\text {lag }}$ considerably. The larger the amount of TSC, the shorter were the $T_{\text {lag }}$ and $T_{\text {rap }}$ (Table II).

As the dose of PDL may vary depending upon the severity of the diseases (25), the effect of variation in dose strength on the drug release behavior from the bipolymeric (CMXG/SAL=1.5:3.5) compression-coated tablets (CC11, $\mathrm{CC} 13$, and CC14) containing MCC (55 mg), CP (9 mg), and TSC $(10 \mathrm{mg})$ was studied. The increase in the amount of PDL from 5 to $15 \mathrm{mg}$ in the core tablets $(\mathrm{CC} 11, \mathrm{CC} 13, \mathrm{CC} 14)$ did not produce any significant change $(p<0.05)$ either in drug release profiles (Fig. 7) or in $T_{\text {lag }}$ and $T_{\text {rap }}$ values (Table II).

The effect of the increase in the coat weight (175 to $250 \mathrm{mg}$ ) on the drug release (Fig. 8) and $T_{\text {lag }}$ and $T_{\text {rap }}$ was studied with tablets CC14 to CC17. The tablet (CC17) coated with the highest amount of polymers did not release the drug completely in $14 \mathrm{~h}$. A decrease in coat weight provided faster drug release. Moreover, $T_{\mathrm{lag}}$ and $T_{\text {rap }}$ were found to decrease from $6.59 \pm 0.07$ to $2.25 \pm 0.04 \mathrm{~h}$ and $8.30 \pm 0.25$ to $3.38 \pm 0.05 \mathrm{~h}$, respectively (Table II).

The state of the tablet (CC16) before dissolution and at different time periods during dissolution was assessed by

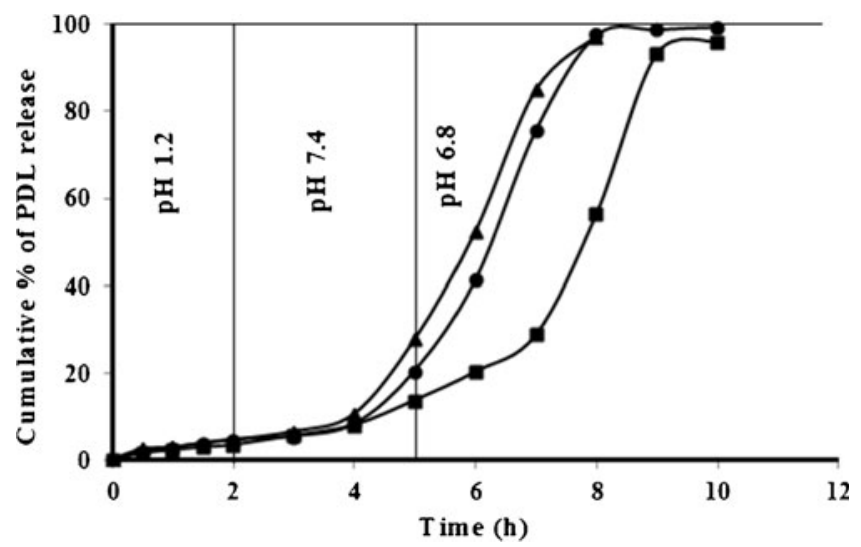

Fig. 6. Effect of TSC in core on cumulative \% of PDL release from compression-coated tablet. Key: $\mathrm{CC} 10$, filled square; $\mathrm{CC} 11$, filled circle; $\mathrm{CC} 12$, filled triangle. Maximum SD $( \pm 3.74, n=6)$

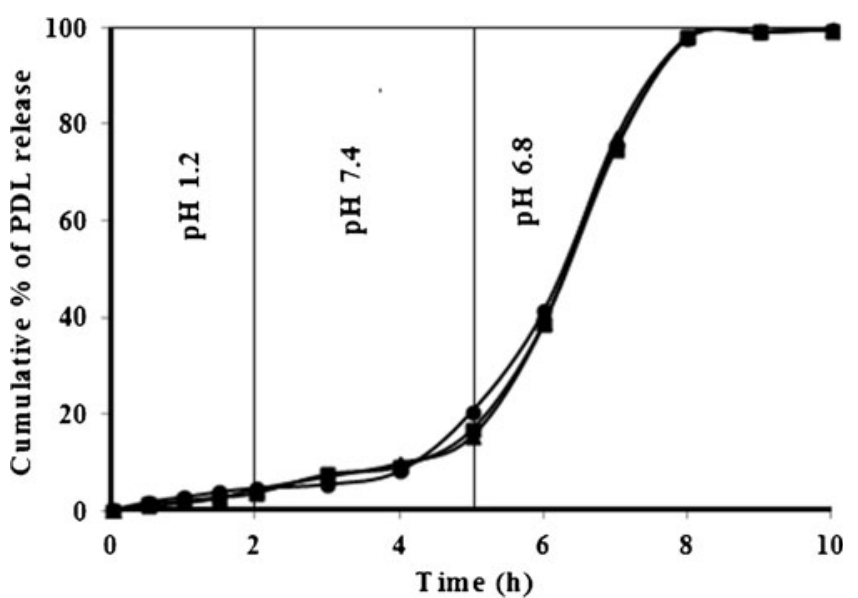

Fig. 7. Effect of PDL load on cumulative \% of PDL release from compression-coated tablet. Key: CC11, filled circle; CC13, filled square; CC14, filled triangle. Maximum SD $( \pm 4.19, n=6)$

observing the dried tablets in a scanning electron microscope (SEM). Figure 9a revealed the presence of a compact coat around the core tablet before dissolution. After $2 \mathrm{~h}$ of exposure in acid solution, the surface of the tablet appeared somewhat uneven (Fig. 9b). The coat eroded to a significant amount, and the core became visible after $6 \mathrm{~h}$ (Fig. 9c) although it did not disintegrate. At the end of $8 \mathrm{~h}$ (Fig. 9d), the core appeared less dense and many pores and fissures developed in the core tablet. After $10 \mathrm{~h}$, the tablets disintegrated completely.

The release data from the end of the lag time up to $70 \%$ of drug release from each of the compression-coated tablets were fitted in zero order, 1st order, and Hixson-Crowell equations. The best fit of the curves was judged from the values of linear regression coefficients $(r)$ which are shown in Table III. The results demonstrated that the release of PDL from CC1, $\mathrm{CC} 2, \mathrm{CC} 12$, and $\mathrm{CC} 17$ tablets followed the zero order kinetic and that from the remaining tablets was governed by the Hixson-Crowell model. Data treatment in Weibull equation

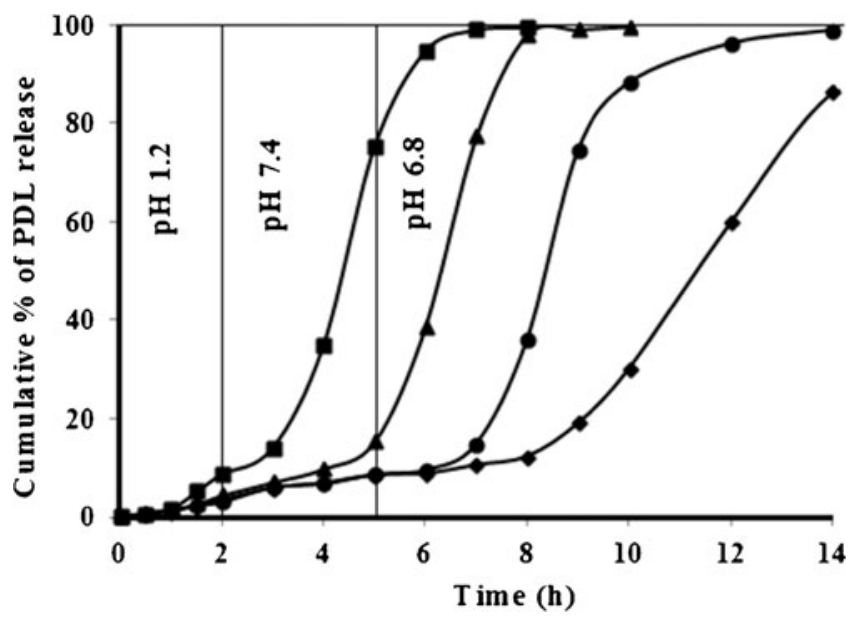

Fig. 8. Effect of coat weight variation on cumulative \% of PDL release from compression-coated tablet. Key: CC14, filled triangle; $\mathrm{CC} 15$, filled square; $\mathrm{CC} 16$, filled circle; $\mathrm{CC} 17$, filled diamond. Maximum SD $( \pm 4.43, n=6)$ 

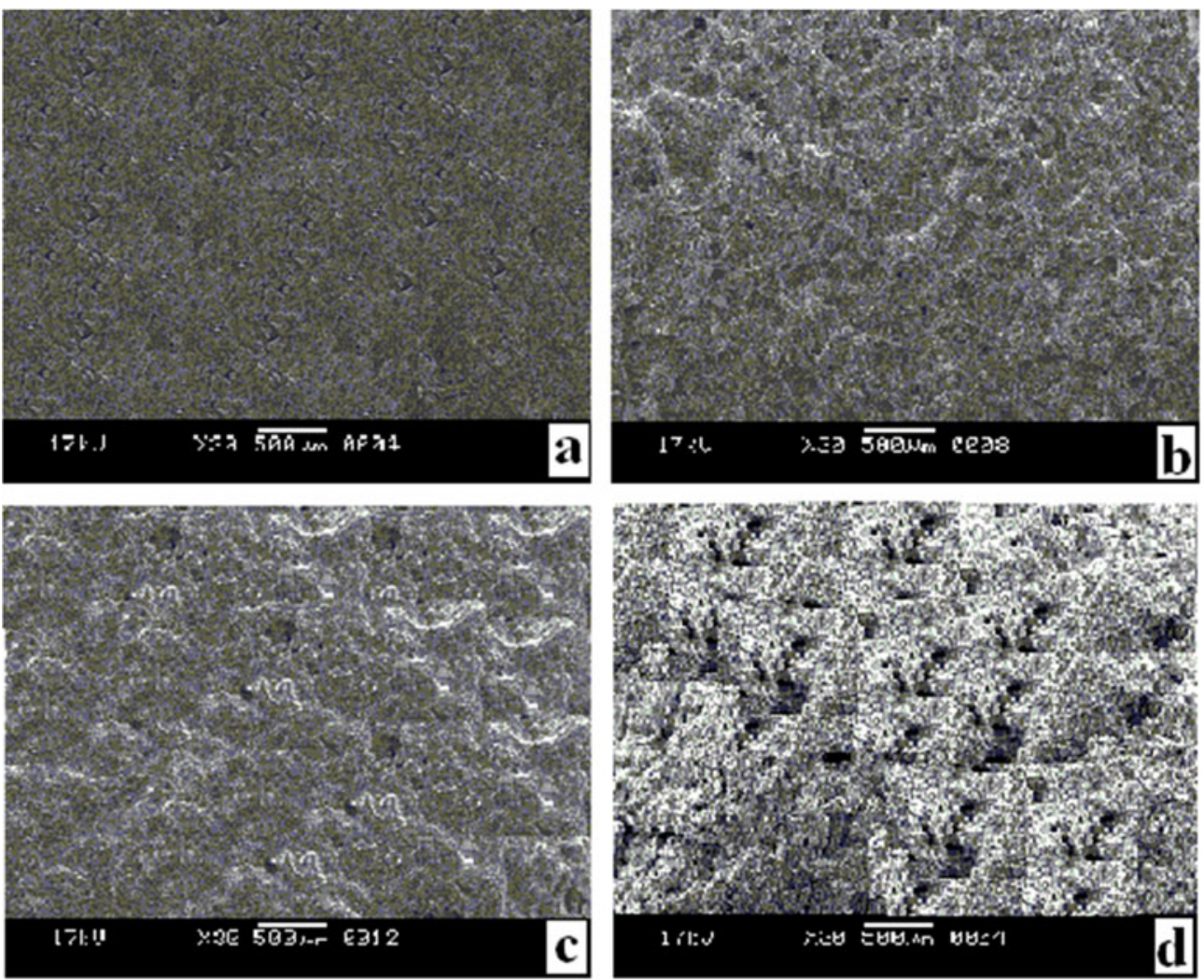

Fig. 9. Scanning electron micrographs of compression-coated tablets: before dissolution (a) and at different time periods (b $2 \mathrm{~h}, \mathbf{c} 6 \mathrm{~h}$, and $\mathbf{d} 8 \mathrm{~h}$ ) during the dissolution study

revealed that the release profiles of PDL from tablets $\mathrm{CC} 1$, $\mathrm{CC} 2, \mathrm{CC} 3, \mathrm{CC} 5, \mathrm{CC} 12$, and $\mathrm{CC} 17$ were not sigmoidal as the values of shape parameter $(\beta)$ were $<1$. However, the release profiles of the drug from other tablets were sigmoidal as the values of $\beta>1$.

\section{DISCUSSION}

Initially, the core tablets of PDL were prepared by direct compression method using MCC and CP as common excipients. $\mathrm{MCC}$ is a versatile excipient in direct compression

Table III. Fitting of PDL Release Data After $T_{\text {lag }}$ in Different Kinetic Models

\begin{tabular}{|c|c|c|c|c|c|c|}
\hline \multirow[t]{2}{*}{ Code } & \multirow{2}{*}{$\begin{array}{l}\text { Zero order } \\
\text { model } \\
(r)\end{array}$} & \multirow{2}{*}{$\begin{array}{l}\text { 1st order } \\
\text { model } \\
(r)\end{array}$} & \multirow{2}{*}{$\begin{array}{l}\text { Hixson-Crowell } \\
\text { model } \\
(r)\end{array}$} & \multicolumn{3}{|c|}{ Weibull model } \\
\hline & & & & $\beta$ & $\log \alpha$ & $(r)$ \\
\hline $\mathrm{CC} 1$ & 0.998 & 0.990 & 0.971 & 0.279 & -0.830 & 0.965 \\
\hline $\mathrm{CC} 2$ & 0.999 & 0.998 & 0.965 & 0.528 & -0.833 & 0.974 \\
\hline $\mathrm{CC} 3$ & 0.935 & 0.888 & 0.981 & 0.840 & -0.703 & 0.799 \\
\hline $\mathrm{CC} 4$ & 0.873 & 0.801 & 0.988 & 1.623 & -1.059 & 0.895 \\
\hline $\mathrm{CC} 5$ & 0.995 & 0.984 & 0.996 & 0.929 & +0.539 & 0.912 \\
\hline CC6 & 0.943 & 0.908 & 0.988 & 1.616 & -0.973 & 0.936 \\
\hline $\mathrm{CC} 7$ & 0.928 & 0.870 & 0.995 & 1.572 & -0.958 & 0.904 \\
\hline $\mathrm{CC} 8$ & 0.934 & 0.900 & 0.983 & 1.737 & -0.877 & 0.961 \\
\hline CC9 & 0.926 & 0.901 & 0.959 & 1.668 & -0.823 & 0.950 \\
\hline CC10 & 0.915 & 0.845 & 0.995 & 1.468 & -0.771 & 0.819 \\
\hline CC11 & 0.929 & 0.886 & 0.972 & 1.849 & -0.645 & 0.967 \\
\hline $\mathrm{CC} 12$ & 0.983 & 0.868 & 0.965 & 0.883 & -0.241 & 0.859 \\
\hline $\mathrm{CC} 13$ & 0.980 & 0.939 & 0.994 & 1.923 & -0.696 & 0.966 \\
\hline $\mathrm{CC} 14$ & 0.980 & 0.937 & 0.995 & 2.063 & -0.782 & 0.976 \\
\hline $\mathrm{CC} 15$ & 0.965 & 0.918 & 0.997 & 1.885 & -0.667 & 0.979 \\
\hline $\mathrm{CC} 16$ & 0.969 & 0.922 & 0.998 & 1.635 & -0.732 & 0.979 \\
\hline $\mathrm{CC} 17$ & 0.990 & 0.921 & 0.955 & 0.964 & -0.810 & 0.791 \\
\hline
\end{tabular}

$r$ correlation coefficient, $\alpha$ the time scale of the dissolution process, $\beta$ the shape parameter 
method of tablet preparation as it acts as both a bulking agent and dry binder and provides compressibility to the tablets that disintegrates rapidly (26). CP was included in the core tablet as a superdisintegrant to facilitate rapid disintegration once the coat is removed to expose the core tablet in aqueous fluid. The core tablets disintegrated within $30 \mathrm{~s}$ irrespective of the amount of MCC and CP. The crushing strength of the core tablet was kept constant at $4 \mathrm{~kg}$ to avoid excessive increase in hardness of the core tablets following double compression with the coating polymers. Excessive increase in crushing strength may prolong the disintegration time (27) due to decrease in porosity (28). Moreover, the crushing strength of $4 \mathrm{~kg}$ was sufficient enough to restrict the friability below $1 \%$ as specified in official compendia. The physical properties of both the core and compression-coated tablet were within pharmacopoeial limits.

The compatibility of PDL with all the excipients in the core tablets was evaluated using FTIR study. The characteristic peaks of the drug in the core tablets were located at almost the same wave numbers as those found with the drug alone, and generation of no new peak or abolition of any of the existing peaks was noted. This confirmed the absence of any drug-excipient interaction.

The colon-targeted drug delivery system should not release the drug in the upper g.i.t. up to $5 \mathrm{~h}$ following which the complete drug release should be achieved at the desired site (29). It implies that drug release should conform to a slow-fast sigmoidal release pattern. Two release parameters viz. $T_{\text {lag }}$ and $T_{\text {rap }}$ appear to be important to achieve this type of release pattern. $T_{\text {lag }}$ is the time required to prevent or minimize the precolonic drug release and should be long usually $6 \mathrm{~h}$, and $T_{\text {rap }}$ is the time required to provide immediate pulse release which should be small usually $4-6 \mathrm{~h}$. $T_{\text {rap }}$ represents the steepness of the release phase and can be calculated from $T_{90-10 \%}$. Many polysaccharides either alone or in combination have been used as compression-coating materials to achieve colon-specific drug release. Among these, pectin and guar gum have been studied extensively. However, pectin coat alone has been found insufficient to protect the core from premature release due to its higher aqueous solubility and poor mechanical strength, and a larger amount of pectin is required to prevent precolonic release $(13,30,31)$. Similar findings have been reported with guar gum used as compressioncoating material $(8,32,33)$. Alternately, calcium cross-linking of carboxyl groups of pectin and SAL has been reported to decrease the aqueous solubility of native polysaccharides and/ or strengthen the gel layer through the formation of an "eggbox" configuration leading to a more controlled release (3436). In general, although these polymers in a higher amount effectively cut down the precolonic release, immediate pulse release was not evident. Instead, following the lag period, the drug was released slowly in a sustained release fashion over a longer period of time. The present study was envisaged to shorten the postlag release time so as to achieve high local drug concentration in the colon. About 95-99\% drug was released from the core tablets within 15 min (data not shown). Rapid release indicates that the release from the core tablets was not a rate-limiting step $(37,38)$. A number of variables both in the core tablets and composition of the compression coat may be a determinant factor in achieving slow-fast type sigmoidal drug release pattern. In this study, initially, the composition of the coat was optimized using various ratios of CMXG and SAL both cross-linked with $\mathrm{Ca}^{+2}$ ion. Coating with cross-linked CMXG alone provided a long $T_{\text {lag }}$; however, complete drug release could not be achieved within $14 \mathrm{~h}$. Release of PDL from a $\mathrm{Ca}^{+2}$ ion cross-linked CMXG matrix tablet has been reported to be incomplete even after $10 \mathrm{~h} \mathrm{(21).}$ Substitution of CMXG with an increasing amount of SAL increased the drug release with a decrease in both $T_{\text {lag }}$ and $T_{\text {rap }}$. On the other hand, cross-linked SAL alone was found unsuitable as a compression-coating material as the drug was completely released within 45 min with a very short $T_{\text {lag }}$ and $T_{\text {rap. }}$. When CMXG is brought in contact with water, the interaction between many hydrophilic groups of CMXG and water leads to the formation of a viscous polymer solution around the tablet surface $(21,39)$. Cross-linking of $\mathrm{CMXG}$ with $\mathrm{Ca}^{+2}$ ion further restricts the mobility of the polymer chain resulting in the formation of a true gel layer around the tablet surface (34) and reduces the macromolecular mess size (19). This in turn decreases the water penetration velocity through the coat (22). Hindrance in seepage of water through the coat shielded the core tablets from disintegrating and liberating the drug. A similar finding in indomethacin release has been reported from $\mathrm{Ca}^{+2}$ ion cross-linked pectin coat (37).

The viscosity of the gel layer can be reduced to enhance water permeation by incorporating a more hydrophilic and low viscous polymer in the coat. Compression coating of the core tablet with SAL provided comparatively faster drug release due to higher hydrophilicity and low viscosity of SAL gel $(17,40)$. To decrease the viscosity of the gel layer and enhance water permeation through the coat, $\mathrm{CMXG}$ was substituted with $\mathrm{Ca}^{+2}$ ion cross-linked SAL. The fall in viscosity of the gel layer due to substitution of CMXG with an increasing amount of SAL was ascertained by measuring the viscosity of the aqueous solution of $\mathrm{CMXG}, \mathrm{SAL}$, and $\mathrm{CaCl}_{2}$ in ratios simulating the ratios used in compression coat. Figure 3 demonstrated that the viscosity of $\mathrm{Ca}^{+2}$ ion containing $\mathrm{CMXG}$ solution was the highest. Substitution of CMXG with an increasing amount of SAL decreased the viscosity, and the solution of SAL exhibited the lowest viscosity. The decrease in the viscosity of the gel layer increased the permeation of water and made the coating polymer to hydrate, dissolve, and/ or erode rapidly. Following dissolution and/or erosion of the coat, the core tablets come in contact with the aqueous solution, disintegrate, and liberate the drug. The higher the amount of SAL, the faster was the drug release and the shorter were the values of $T_{\text {lag }}$ and $T_{\text {rap }}$. As tablet CC5, coated with SAL alone, was unable to protect the core from rapid drug release, and tablets $\mathrm{CC} 1, \mathrm{CC} 2$, and $\mathrm{CC} 3$, prepared with a higher proportion of $\mathrm{CMXG}$ in the coat, produced exceedingly long $T_{\text {lag }}$ and $T_{\text {rap }}$, tablet CC4 compression coated with $\mathrm{CMXG/SAL}$ in a ratio of 1.5:3.5 was considered optimum for further study.

Keeping the coat composition (CMXG/SAL=1.5:3.5) fixed, the composition of the core tablets was manipulated to investigate the effect on drug release profiles, $T_{\text {lag }}$ and $T_{\text {rap. }}$. The increase in the amount of MCC in the core did not produce any significant change in $T_{\text {lag }}$ and marginally decreased the $T_{\text {rap }}$ values. On the other hand, the increase in the amount of CP considerably reduced the $T_{\text {rap }}$ values, although $T_{\text {lag }}$ values were found virtually the same (Table II). MCC is considered as a versatile excipient in tablet 
manufacturing by direct compression method as it acts as both a bulking agent, dry binder, and disintegrating agent for tablets and also provides compressibility to the matrix (26). MCC facilitates the penetration of water into the core by wicking action and exerts hydrostatic pressure to disintegrate the tablets (41). The increase in the amount of MCC decreased the $T_{\text {rap }}$ marginally. Probably, a decrease in disintegration time with a higher amount of MCC might have compromised with the increase in compressibility of the core matrix. On the other hand, the increase in CP considerably decreased the $T_{\text {rap }}$ value when compared with MCC. CP is regarded as a superdisintegrating agent and is more powerful than MCC concerning the disintegration of tablets. It should, however, be noted that $T_{\text {lag }}$ was not apparently changed due to the increase in the amount of either MCC or CP. It is reasonable to assume that the time taken by the compression-coating material to dissolve/or erode might be almost same, and slight seepage of water through the gel layer was not sufficient to explode the core. Inclusion of TSC as an osmogen considerably reduced both $T_{\text {lag }}$ and $T_{\text {rap }}$ values. The larger the amount of TSC, the shorter were the values of $T_{\text {lag }}$ and $T_{\text {rap }}$ (Table II). Even slight seepage of water through the gel layer may develop high osmotic pressure in the core that acts radically outwards to rupture the coat or surrounding membrane (42). The lag time of drug release from compression-coated ethyl cellulose tablets has been reported to decrease markedly due to the presence of $\mathrm{NaCl}$ as osmogen in the core tablets (43).

The mechanism of drug release from compressioncoated tablets is not well documented. The nature and amount of the polysaccharide coat as well as the composition of the core appears decisive in elucidating the drug release mechanism. When a polysaccharide coat comes in contact with water, a gel layer is formed around the core. A strong gel, formed either due to the nature of the polymer or its presence in a large amount, reduces swelling, hinders penetration of water, and may promote erosion of the coat $(44,45)$. Slow penetration of water dissolves the drug in the core slowly providing long $T_{\text {lag }}$ and $T_{\text {rap. Probably, prefer- }}$ ential erosion over swelling of the coat results in zero order drug release (45). Cross-linked CMXG forms a stronger gel than SAL as evidenced from the viscosity as displayed in Fig. 3. The presence of a higher proportion of CMXG in tablets $\mathrm{CC} 1$ and $\mathrm{CC} 2$ and a higher amount of total polymer as in CC17 probably induced erosion-controlled zero order release after $T_{\text {lag. }}$. On the other hand, low gel strength produced by a higher proportion of SAL, as in tablets $\mathrm{CC} 3, \mathrm{CC} 4$, and $\mathrm{CC} 5$, and the presence of lower coat weight, as in tablets $\mathrm{CC} 14, \mathrm{CC} 15$, and CC16, allowed the coat to dissolve somewhat rapidly, exposing the core to the dissolution medium and allowing the release of the drug following the Hixson-Crowell model. At a particular coat composition, the increase in MCC, CP, and TSC in the core probably made the coat to fracture exposing the core in the dissolution medium rapidly and allowing the liberated drug to dissolve following the Hixson-Crowell model. The tablets having very high or low $T_{\text {lag }}$ and $T_{\text {rap }}$ values $(\mathrm{CC} 1, \mathrm{CC} 2$, $\mathrm{CC} 3, \mathrm{CC} 5, \mathrm{CC} 12$, and $\mathrm{CC} 17$ ) did not display a sigmoidal release pattern that was substantiated from the shape parameter $(\beta)$ which was not greater than 1 . However, other compression-coated tablets released the drug in a sigmoidal pattern $(\beta>1)$.
Tablet CC16 consisting of MCC $(55 \mathrm{mg}), \mathrm{CP}(9 \mathrm{mg})$, TSC (10 mg), and PDL (15 mg) in the core and compression coated with $225 \mathrm{mg}$ of a blend of $\mathrm{Ca}-\mathrm{CMXG}$ and SAL in a ratio of 1.5:3.5 appeared to provide an optimum drug release profile for colon targeting. The surface topography of tablet CC16 during different stages of the dissolution study was evaluated by SEM. The change in the state of the tablet surface corroborated well with the drug release profile. The surface of the compression-coated tablet was compact and smooth before dissolution (Fig. 9a). After $2 \mathrm{~h}$ of exposure in acid solution of $\mathrm{pH} \mathrm{1.2,} \mathrm{the} \mathrm{surface} \mathrm{of} \mathrm{the}$ tablets appeared rough/uneven due to slow erosion of the coating material taking place during dissolution. The core tablet was still covered with a considerable amount of coating material and, hence, was not visible (Fig. 9b). Consequently, the amount of drug released in $2 \mathrm{~h}$ was very less (about 3\%). Figure 9c shows the state of the tablet after $6 \mathrm{~h}$ of dissolution. Although the core tablet became visible after $6 \mathrm{~h}$ of dissolution study (Fig. 9c), it did not show any sign of disintegration probably due to the presence of the gel layer around the core tablet that prevented a significant amount of the drug to be released. The figure of the drug release profile (Fig. 8) showed that only $10 \%$ of the drug was released in $6 \mathrm{~h}$. After $8 \mathrm{~h}$ (Fig. 9d), the gel layer almost eroded making somewhat a better contact between the core tablet and water. As a result, the core tablet tended to bulge out and appeared less dense, and many pores and fissures became evident on the surface of the core indicating the beginning of disintegration. At this point, a somewhat larger amount of the drug (about $36 \%$ ) was released. The tablet disintegrated completely after $10 \mathrm{~h}$ and liberated about $90 \%$ of the drug. Thus, the compression-coating material eroded slowly and minimized the premature drug release up to $6 \mathrm{~h}$. After the $T_{\text {lag }}$ (about $6 \mathrm{~h}$ ) of drug release, the coating material eroded completely, exposed the core tablet to the aqueous dissolution medium, and induced almost complete release within the next $4 \mathrm{~h}$.

\section{CONCLUSION}

A novel compression-coated tablet was developed using a blend of polysaccharides for colon targeting of prednisolone. The composition of both the coating polymers and the core tablet was found critical to achieve a prolonged $T_{\text {lag }}$ (about $6 \mathrm{~h}$ ) for minimization of the drug release in the upper g.i.t. and a shorter $T_{\text {rap }}$ for rapid release of the drug in the colonic region following the

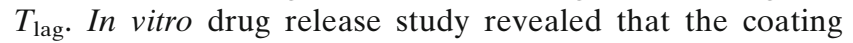
of the core tablet with neither CMXG nor SAL alone was suitable for colon targeting of the drug. A blend of CMXG and SAL in a ratio of 1.5:3.5 was able to provide a reasonably long $T_{\text {lag }}$ and short $T_{\text {rap. Inclusion of }}$ osmogen in addition to common disintegrants in the core tablet and the increase in coat weight resulted in the development of a compression-coated tablet that appeared to achieve the desired values of $T_{\text {lag }}$ and $T_{\text {rap. }}$ This type of compression-coated tablet appears to be suitable for colon 
targeting of prednisolone even in the absence of colonic fluid/colonic bacterial enzymes.

\section{ACKNOWLEDGMENTS}

One of the authors (S. Maity) wishes to express thanks to the Council of Scientific and Industrial Research, New Delhi, India, for the financial support as CSIR-SRF [Grant No. 9/96 (0727)2K12/EMR-1].

\section{REFERENCES}

1. Sinha VR, Mittal BR, Bhutani KK, Kumria R. Colonic drug delivery of 5-fluorouracil: an in vitro evaluation. Int J Pharm. 2004:269:101-8.

2. Friend DR. Colon-specific drug delivery. Adv Drug Deliv Rev. 1991;7:149-99.

3. Fried DR. New oral delivery system for treatment of inflammatory bowel disease. Adv Drug Deliv Rev. 2005;57:247-65.

4. Lee VHL, Mukherjee SK. Drug delivery: oral colon-specific. In: Swarbrick J, Boylan JC, editors. Encyclopedia of pharmaceutical technology. New York: Marcel Dekker; 2002. p. 871-85.

5. Sinha VR, Kumria R. Microbially triggered drug delivery to the colon. Eur J Pharm Sci. 2003;18:3-18.

6. Yang L, Chu JS, Fix JA. Colon-specific drug delivery: new approaches and in vitro/in vivo evaluation. Int J Pharm. 2002;235:115.

7. Ibekwe VC, Khela MK, Evans DF, Basit AW. A new concept in colonic drug targeting: a combined pH-responsive and bacterially-triggered drug delivery technology. Aliment Pharmacol Ther. 2008;28:911-6.

8. Rama Prasad YV, Krishnaiah YSR, Satyanarayana S. In vitro evaluation of guar gum as a carrier for colon-specific drug delivery. J Control Release. 1998;51:281-7.

9. Bharaniraja B, Kumar KJ, Prasad CM, Sen AK. Modified katira gum for colon targeted drug delivery. J Appl Polym Sci. 2011;119:2644-51.

10. Ibekwe VC, Fadda HM, Parsons GE, Basit AW. A comparative in vitro assessment of the drug release performance of $\mathrm{pH}$ responsive polymers for ileo-colonic delivery. Int $\mathrm{J}$ Pharm. 2006;308:52-60.

11. Vandamme TF, Lenourry A, Charrueau C, Chaumeil JC. The use of polysaccharides to target drugs to the colon. Carbohydr Polym. 2002;48:219-31.

12. Wu B, Shun N, Wei X, Wu W. Characterization of 5-fluorouracil release from hydroxypropylmethylcellulose compression-coated tablets. Pharm Dev Technol. 2007;12:203-10.

13. Ashford M, Fell J, Attwood D, Sharma H, Woodhead P. An evaluation of pectin as a carrier for drug targeting to the colon. J Control Release. 1993;26:213-20.

14. Krishnaiah YSR, Satyanarayana S, Rama Prasad YV, Narasimha RS. Evaluation of guar gum as a compression coat for drug targeting to colon. Int J Pharm. 1998;171:137-46.

15. Krishnaiah YSR, Satyanarayana V, Dinesh Kumar B, Karthikeyan RS. In vitro drug release studies on guar gumbased colon targeted oral drug delivery systems of 5-fluorouracil. Eur J Pharm Sci. 2002;16:185-92.

16. Yehia SA, Elshafeey AH, Sayed I, Shehata AH. Optimization of budesonide compression-coated tablets for colonic delivery. AAPS PharmSciTech. 2009;10:147-57.

17. Vemula SK, Veerareddy PR, Devadasu VR. Pharmacokinetics of colon-specific $\mathrm{pH}$ and time-dependent flurbiprofen tablets. Eur J Drug Metab Pharmacokinet. 2014. doi:10.1007/ s13318-014-0210-0.

18. Bashardoust N, Jenita JJL, Zakeri-Milani P. Physicochemical characterization and dissolution study of ibuprofen compression-coated tablets using locust bean gum. Dissol Technol. 2013;20:38-43.
19. Omwancha W, Kouba C, Yelamanchili S, Neau SH. Colonspecific drug delivery using ethylcellulose and chitosan in the coat of compression-coated tablets. Drug Dev Ind Pharm. 2011:37:945-53.

20. Sinha VR, Singh A, Singh S, Bhinge JR. Compression coated systems for colonic delivery of 5-fluorouracil. J Pharm Pharmacol. 2007:59:359-65.

21. Maity S, Sa B. Development and evaluation of $\mathrm{Ca}^{+2}$ ion crosslinked carboxymethyl xanthan gum tablet prepared by wet granulation technique. AAPS PharmSciTech. 2014;15:920-7.

22. Maity S, Sa B. Ca-carboxymethyl xanthan gum mini-matrices: swelling, erosion and their impact on drug release mechanism. Int J Biol Macromol. 2014;68:78-85.

23. Indian Pharmacopoeia Commission. Indian pharmacopoeia, vol. I. Ghaziabad: Indian Pharmacopoeia Commission; 2010.

24. Costa P, Lobo JMS. Modeling and comparison of dissolution profiles. Eur J Pharm Sci. 2001;13:123-33.

25. Bayless TM, Hanauer SB. Advance therapy of inflammatory bowel disease. IBD and ulcerative colitis, vol. I. 3rd ed. Shelton: Peoples's Medical Publishing House; 2001.

26. Shangraw RF. Compressed tablets by direct compression. In: Lieberman HA, Lachman L, Schwartz JB, editors. Pharmaceutical dosage forms: tablets, vol. 1. New York: Marcel Dekker; 1989. p. $195-246$.

27. Katikaneni PR, Upadrashta SM, Neaua SH, Mitra AK. Ethylcellulose matrix controlled release tablets of a watersoluble drug. Int J Pharm. 1995;123:119-25.

28. Salsa T, Veiga F, Pina ME. Oral controlled-release dosage forms. I. Cellulose ether polymers in hydrophilic matrices. Drug Dev Ind Pharm. 1997;23:929-38.

29. Sinha VR, Mittal BR, Kumria R. In vivo evaluation of time and site of disintegration of polysaccharide tablet prepared for colonspecific drug delivery. Int J Pharm. 2005;289:79-85.

30. Turkoglu M, Ugurlu T. In vitro evaluation of pectin-HPMC compression coated 5-aminosalicylic acid tablets for colonic delivery. Eur J Pharm Biopharm. 2002;53:65-73.

31. Nasra MA, EL-Massik MA, Naggar VF. Development of metronidazole colon-specific delivery systems. Asian J Pharm Sci. 2007;2:18-28.

32. Krishnaiah YSR, Satyanarayana S, Prasad YV. Studies of guar gum compression-coated 5-aminosalicylic acid tablets for colon-specific drug delivery. Drug Dev Ind Pharm. 1999;25:651-7.

33. Vemula SK, Bontha VK. Colon targeted guar gum compression coated tablets of flurbiprofen: formulation, development, and pharmacokinetics. Biomed Res Int. 2013;287919:1-8.

34. Mandal S, Basu SK, Sa B. Sustained release of a water-soluble drug from alginate matrix tablets prepared by wet granulation method. AAPS PharmSciTech. 2009;10:1348-56.

35. Hiorth M, Versland T, Heikkilä J, Tho I, Sande SA. Immersion coating of pellets with calcium pectinate and chitosan. Int J Pharm. 2006;308:25-32.

36. Jain A, Gupta Y, Jain SK. Potential of calcium pectinate beads for target specific drug release to colon. J Drug Target. 2007;15:28594.

37. Wei X, Lu Y, Qi J, Wu B, Chen J, Xu H, et al. An in situ crosslinked compression coat comprised of pectin and calcium chloride for colon-specific delivery of indomethacin. Drug Deliv. 2014. doi:10.3109/10717544.2013.879965.

38. Rujivipat S, Bodmeier R. Improved drug delivery to the lower intestinal tract with tablets compression-coated with enteric/ nonenteric polymer powder blends. Eur J Pharm Biopharm. 2010;76:486-92.

39. Kadajji VG, Betageri GV. Water soluble polymers for pharmaceutical applications. Polymers. 2011;3:1972-2009.

40. Sirkiä T, Salonen H, Veski P, Jürjenson H, Marvola M. Biopharmaceutical evaluation of new prolonged-release press-coated ibuprofen tablets containing sodium alginate to adjust drug release. Int J Pharm. 1994;107:179-87.

41. Sungthongjeen S, Puttipipatkhachorn S, Paeratakul O, Dashevsky A, Bodmeier R. Development of pulsatile release tablets with swelling and rupturable layers. J Control Release. 2004;95:147-59.

42. Verma RK, Mishra B, Garg S. Osmotically controlled oral drug delivery. Drug Dev Ind Pharm. 2000;26:695-708. 
43. Lin SY, Lin KH, Li MJ. Influence of excipients, drugs, and osmotic agent in the inner core on the time-controlled disintegration of compression-coated ethylcellulose tablets. J Pharm Sci. 2002;91:2040-6.

44. Sriamornsak P, Thirawong N, Weerapol Y, Nunthanid J, Sungthongjeen S. Swelling and erosion of pectin matrix tablets and their impact on drug release behavior. Eur J Pharm Sci. 2007;67:211-9.

45. Sujja-areevath J, Munday DL, Cox PJ, Khan KA. Relationship between swelling, erosion and drug release in hydrophillic natural gum mini-matrix formulations. Eur J Pharm Sci. 1998;6:207-17. 